\title{
RISK FACTORS OF SUICIDE AND PARA SUICIDE IN RURAL BANGLADESH
}

\author{
A M SELIM REZA ${ }^{1}$, A H M FEROZ ${ }^{2}$, S M NURUL ISLAM ${ }^{3}$, MD. NAZMUL KARIM ${ }^{4}$, MD. GOLAM RABBANI ${ }^{5}$, MD. \\ $\mathrm{SHAH} \mathrm{ALAM}^{6}$, A K M MUJIBUR RAHMAN ${ }^{7}$, MD. RIDWANUR RAHMAN ${ }^{8}$, HELAL UDDIN AHMED ${ }^{9}$, \\ AVRA DAS BHOWMIK ${ }^{10}$, MUHAMMAD ZILLUR RAHMAN KHAN ${ }^{11}$, MEKHALA SARKAR ${ }^{12}$, \\ MOHAMMAD TARIQUL ALAM ${ }^{13}$, M M JALAL UDDIN ${ }^{14}$
}

\begin{abstract}
:
Background: Suicide is a public health problem too often neglected by researchers, health policy makers and the medical profession. According to WHO estimates for the year 2020 and based on current trends approximately 1.53 million people will die from suicide and 10-20 times more people will attempt suicide worldwide. No nationwide survey on suicidal risk factors has yet been conducted in Bangladesh. The aim of this study was to unearth the potential risk factors of suicide or suicidal attempts and to assess psychiatric illness, non psychiatric co-morbidity, individual's behavioral and physical factor, familial risk factors and socio-demographic risk factors of suicide and its attempts.
\end{abstract}

Study Design and Setting: A case control study was carried out by members of the Department of Medicine, Shaheed Suhrawardi Medical College and Hospital at Mominpur, Haowlee and Jibonnagar unions under three Upazilla of district Chuadanga,. Statistical analyses were performed using SPSS 16.

Results: A total 230 subjects (113 cases and 117 controls) were interviewed. Mean age among cases was $29.6 \pm 12.8$ years and controls were $29.7 \pm 12.9$ years.. Economic status was also similar in two groups. Problem of love affair (OR 5.2), Personal problem (OR 11.9), Feeling of economic hardship (OR 2.4) appeared to have statistically significant association with suicidal attempt. Problem with relatives (OR 3.8), death of near relative (OR 0.9) and poor academic performance (OR 1.6) didn't appear to have any association with risk of suicidal attempt. History of chronic disease (OR 2.9) showed statistically significant association but long term physical disability (OR 4.4) and physical problems didn't appear to have any significant association with suicidal attempt. History of suicidal attempt by any relative $(O R$ 4.2) and previous attempt to suicide (OR 7.4) appeared as highly significant factor for suicide. Not being reared by biological parents (OR 3.2), marital disharmony (OR 4.0), Conflict within the family (OR 6.9) appeared to be strongly associated with suicidal attempts. Suicidal attempts of participants were significantly associated with sleeping disturbance (OR 2.3), uncertainty about future (7.2), impulsivity (OR 13.8), and history of criminal behavior (OR 2.1).

Conclusion: Married female especially the younger age from unitary family of low income group are more vulnerable to commit suicide or parasuicide. Several emotional factors, presence of chronic diseases, familial suicidal predisposition, individual factor and mental state, premorbid persionality and psychiatric syndrome appeared to have significant association with suicidal attempts.

\section{Introduction:}

Suicide, the voluntary extinction of life, is one of the three leading causes of death among 15-44 years old people globally ${ }^{1}$. It is well documented that suicide is the leading cause of death among young people.
According to WHO estimates for the year 2020 and based on current trends approximately 1.53 million people will die from suicide and 10-20 times more people will attempt suicide worldwide. This represents on average 1 death per 20 seconds and 1 attempt

1. Assistant Professor, Department of Forensic Medicine, ShSMC, Dhaka

2. Associate Professor, Department of Medicine, ShSMC, Dhaka

3. Assistant Professor, Department of Medicine, ShSMC, Dhaka

4. National Consultant, WHO, Bangladesh

5. Professor of Psychiatry and Director, NIMH, Dhaka

6. Professor of Psychiatry, NIMH, Dhaka

7. Professor, Department of Medicine \& Director, ShSMCH, Dhaka

8. Professor and Head, Department of Medicine, ShSMC, Dhaka

9. Consultant Psychiatrist, NIMH, Dhaka

10. Assistant Professor, NIMH, Dhaka

11. Assistant Professor, NIMH, Dhaka

12. Assistant Professor, NIMH, Dhaka

13. Assistant Professor, NIMH, Dhaka

14. Consultant Psychiatrist, NIMH, Dhaka

Bangladesh J Medicine 2013; 24 : 14-19 
every 1-2 seconds ${ }^{2}$. Bangladesh also holds an unacceptably high suicide rate of 8-10/100000 people/year ${ }^{3}$ and about 10\%-20\% of emergency admission in hospitals are suicidal cases ${ }^{4}$. Suicide was the $5^{\text {th }}$ most common cause of death overall and ranked number one among adolescents (10-19 years of age) in a rural area of Bangladesh studied recently ${ }^{5}$.

Suicide is the $9^{\text {th }}$ cause of death in USA and $8^{\text {th }}$ cause in UK and it accounts for about $1.8 \%$ of global burden of disease ${ }^{6}$. It is the third most important contributor to life year lost and it is one of the four leading causes of mortality, other beings natural, accidental and homicidal. In Bangladesh, suicide is an unrecognized, hidden and silent epidemic that can be prevented if proper attention is given.

Psychiatric disorder, past history of attempted suicide, family history of attempted suicide, impulsibility and demographic variables are observed in various cases of suicide and para suicide.

Recently a study was performed on prevalence of suicide and para suicide in rural area of Chuadanga district jointly by Shaheed Suhrawardy Medical College Hospital and office of the DGHS, Dhaka. The study shows the incidence of suicidal death is 128.8 per 100000 populations per year ${ }^{7}$. The attempt and death were more common in female. About $57 \%$ had discord in the family. Various factors were observed for the events of suicide and para suicide but actual risk factors were not identified.

No nationwide survey on suicidal risk factors has yet been conducted in Bangladesh. Reports from police records. Media, court, hospitals and the focused study on selected population indicate that suicide is a public health problem in Bangladesh.

\section{Objectives:}

The general objective of the study was to unearth the potential risk factor of suicide or suicidal attempts and the specific objectives were to assess psychiatric illness, non psychiatric co-morbidity as risk factor for suicide and its attempts, to assess individual's behavioral and physical factor that may precipitate suicide and its attempts, to assess familial risk factors of suicide and its attempts and to determine socio-demographic risk factors of suicide and its attempts.

\section{Methodology:}

Cases were all prevalent individuals who have committed or attempted suicide during a 24-month period in the study area identified by another survey ${ }^{7}$. Informants (most commonly close family members) were approached to take part in the study in the informant's home. Controls were recruited matched for age (within three years), gender and socioeconomic status. For each individual who committed suicide 2 persons in the area who died of other reason were selected and for those who survived the attempt controls were recruited based on same matching criteria and who had been suffering any accident or illness at or closer to the time of the attempt.

The primary sources of information were the informants. They has interviewed by experienced clinicians using The Structured Clinical Interview for DSM-IV Axis I Disorders (SCID-I) 8.

\section{Inclusion criteria:}

All the cases of committed suicide and attempted suicide within last two years.

\section{Exclusion criteria}

The person did not attempted suicide and not willing to take part in the study.

Sample size:

For a case control study OR was considered for calculating sample size, after calculation the sample size was found 264 .

\section{Statistical analysis}

Univariate analysis was carried out initially to investigate the association between individual factors and the risk of suicide. Then, conditional logistic regression was used to account for the matched design. Variables has been grouped together in five domains Socio-demographic factors, Familial factors, Individual's characteristics, Non psychiatric illness and Psychiatric illness. Multivariate models were generated then within each domain using backwards elimination procedures. The predictors from each of the domain specific models were fitted in a final multivariate model to identify risk factors independently associated with suicide. Explanatory variables has retained in the final model with the $\mathrm{P}$ value less than 0.05 .

STATA $10 /$ IC software was used to calculate odds ratios and their 95\% confidence intervals through C-logit analysis

\section{Ethical Implications:}

The study was conducted by obtaining ethical clearance of Ethical Committee of Bangladesh Medical Research Council (BMRC). Before data collection, informed verbal consent was taken from the respondent. Moreover confidentiality of collected data was maintained with highest priority. 


\section{Result and observation}

Socio demographic factor

In this case control study a total 230 subjects (113 cases and 117 controls) were interviewed. Among the respondents $16.8 \%$ of cases and $17.9 \%$ of the controls were aged below $<20$ years Majority of the participants, $65.5 \%$ of cases and $63.2 \%$ of controls were aged between 20-39 years. Mean age among cases was $29.6 \pm 12.8$ years and controls were $29.7 \pm 12.9$ years. The two groups showed no statistically significant difference in age $(P>0.05)$. Among cases $38.9 \%$ were male and among the controls $42.7 \%$ were male. The sex distribution in two groups are similar $(\mathrm{P}>0.05)$. Among cases $30.1 \%$ and among controls $27.4 \%$ had less than 4 family members. More than half of the participants, among cases (58.4\%) and among controls (55.6\%) had between 4- 6 members in the family. No statistically significant difference exists in family size and type in two groups. Economic status was also similar in two groups. (Table 1)

Table-I

Socio demographic variables

\begin{tabular}{|c|c|c|c|}
\hline Variables & Case & Control & Test statistics \\
\hline \multicolumn{4}{|l|}{ Age } \\
\hline$<20$ years & $19(16.8)$ & 21 (17.9) & \multirow{4}{*}{$\begin{array}{c}\div^{2}=.412 \mathrm{df}=3 \\
\mathrm{P}=0.938\end{array}$} \\
\hline 20 - 39 years & $74(65.5)$ & 74 (63.2) & \\
\hline $40-59$ years & $14(12.4)$ & 17 (14.5) & \\
\hline$>=60$ years & $6(5.3)$ & $5(4.3)$ & \\
\hline \multicolumn{4}{|l|}{ Sex } \\
\hline Male & $44(38.9)$ & $50(42.7)$ & \multirow{2}{*}{$\begin{array}{c}\div^{2}=0.34 \mathrm{df}=2 \\
P=0.558\end{array}$} \\
\hline Female & $69(61.1)$ & 67 (57.3) & \\
\hline \multicolumn{4}{|l|}{ Marital status } \\
\hline Unmarried & $24(21.2)$ & $29(24.8)$ & \multirow{2}{*}{$\begin{array}{c}\div^{2}=0.41 \mathrm{df}=2 \\
P=0.523\end{array}$} \\
\hline Married & $89(78.8)$ & $84(75.2)$ & \\
\hline \multicolumn{4}{|l|}{ Family size } \\
\hline$<4$ & $34(30.1)$ & $32(27.4)$ & \multirow{3}{*}{$\begin{array}{c}\dot{\div}^{2}=1.50 \mathrm{df}=2 \\
\mathrm{P}=0.476\end{array}$} \\
\hline $4-6$ & $66(58.4)$ & 65 (55.6) & \\
\hline$>6$ & $13(11.5)$ & $20(17.1)$ & \\
\hline \multicolumn{4}{|l|}{ Family type } \\
\hline Unitary & $82(72.6)$ & 85 (72.6) & \multirow[t]{2}{*}{$\begin{array}{c}\div^{2}=0.03 \mathrm{df}=2 \\
\mathrm{P}=0.989\end{array}$} \\
\hline Joint & $31(27.4)$ & $29(27.4)$ & \\
\hline \multicolumn{4}{|c|}{ Family monthly income } \\
\hline less than 3000 & 12 (10.6) & $11(9.4)$ & \multirow{4}{*}{$\begin{array}{c}\div^{2}=2.57 \mathrm{df}=3 \\
P=0.462\end{array}$} \\
\hline $3000-5000$ & 79 (69.9) & $75(64.1)$ & \\
\hline $5000-10000$ & $17(15.0)$ & $20(17.1)$ & \\
\hline More than 10000 & $5(4.4)$ & $11(9.4)$ & \\
\hline
\end{tabular}

\section{Emotional factors}

Table 2 compares the emotional factors for suicidal attempts. Problem of love affair (OR 5.2), Personal problem (OR 11.9), Feeling of economic hardship (OR 2.4) appeared to have statistically significant association with suicidal attempt. Among other factors problem with relatives (OR 3.8), death of near relative
(OR 0.9) and poor academic performance (OR 1.6) didn't appear to have any association with risk of suicidal attempt.

Table-II

Emotional factors

\begin{tabular}{lccr}
\hline Emotional factor & Case & Control & OR $(95 \%$ CI $)$ \\
\hline Love affair problem & $5(4.4)$ & $1(.85)$ & $5.2(1.8,21.4)$ \\
$\begin{array}{l}\text { Personal problem } \\
\text { Problem with }\end{array}$ & $27(23.9)$ & $3(2.6)$ & $11.9(3.5,40.6)$ \\
$\begin{array}{l}\text { relatives } \\
\begin{array}{l}\text { Death of near } \\
\text { relative }\end{array}\end{array}$ & $5(4.4)$ & $6(5.1)$ & $0.9(0.3,2.9)$ \\
$\begin{array}{l}\text { Felt economic } \\
\text { hardship }\end{array}$ & $21(18.6)$ & $10(8.5)$ & $2.4(1.1,5.4)$ \\
$\begin{array}{l}\text { Poor academic } \\
\text { performance }\end{array}$ & $6(5.3)$ & $4(3.4)$ & $1.6(0.4,5.8)$ \\
\hline
\end{tabular}

\section{Co morbidity related factor}

Among Co morbidity related factors history of chronic disease (OR 2.9) showed statistically significant association but long term physical disability (OR 4.4) and physical problems didn't appear to have any significant association with suicidal attempt.

Table-III

Co morbidity related factor

\begin{tabular}{lccc}
\hline $\begin{array}{l}\text { Co morbidity } \\
\text { related factor }\end{array}$ & Case & Control & OR $(95 \%$ CI) \\
\hline $\begin{array}{l}\text { Long term physical } \\
\text { disability }\end{array}$ & $8(7.1)$ & $2(1.7)$ & $4.4(0.91,21.10)$ \\
Chronic Disease & $22(19.5)$ & $9(7.7)$ & $2.9(1.27,6.6)$ \\
Physical problem & $16(14.2)$ & $8(6.8)$ & $2.2(.92,5.48)$ \\
\hline
\end{tabular}

\section{Familial psychiatric history}

Among cases $11.5 \%$ provided history of psychiatric problem in near relatives and among controls the percentage is $5.1(\mathrm{OR}=2.4)$, however no statistically significant association was found with psychiatric problem among near relatives. History of suicidal attempt by any relative (OR 4.2) and previous attempt to suicide (OR 7.4) appeared as highly significant factor for suicide.

Table-IV

Familial psychiatric history

\begin{tabular}{lccc}
\hline $\begin{array}{l}\text { Familial } \\
\text { psychiatric history }\end{array}$ & Case & Control & OR $(95 \% \mathrm{CI})$ \\
\hline $\begin{array}{l}\text { Psychiatric } \\
\text { problem in near } \\
\text { relative }\end{array}$ & $13(11.5)$ & $6(5.1)$ & $2.4(0.88,6.57)$ \\
$\begin{array}{l}\text { Suicidal attempt } \\
\text { by any relative }\end{array}$ & $55(48.7)$ & $18(15.4)$ & $4.2(1.63,7.23)$ \\
$\begin{array}{l}\text { Previous attempt } \\
\text { to suicide }\end{array}$ & $49(43.3)$ & $11(9.4)$ & $7.4(3.57,15.21)$ \\
\hline
\end{tabular}




\section{Familial suicide predisposition}

Not being reared by biological parents (OR 3.2), marital disharmony (OR 4.0), Conflict within the family (OR 6.9) all of three factors appeared to be strongly associated with suicidal attempts.

Table-V

Familial suicide predisposition

\begin{tabular}{lccc}
\hline $\begin{array}{l}\text { Familial suicide } \\
\text { predisposition }\end{array}$ & Case & Control & OR $(95 \%$ CI) \\
$\begin{array}{l}\text { Not reared by } \\
\text { biological parents }\end{array}$ & $6(5.3)$ & $2(1.7)$ & $3.2(0.64,16.32)$ \\
$\begin{array}{l}\text { Marital disharmony } \\
\begin{array}{l}\text { Conflict within } \\
\text { the family }\end{array}\end{array}$ & $53(46.9)$ & $21(17.9)$ & $4.0(2.22,7.35)$ \\
\hline
\end{tabular}

\section{Individual factor and mental state}

Table 6: Suicidal attempts of participants were significantly associated with sleeping disturbance (OR 2.3), uncertainty about future (7.2), impulsivity (OR 13.8), and history of criminal behavior (OR 2.1). Among these factors sleeping disturbance and history of criminal behavior were highly significant. And history of recent childbirth (OR 1.7) and history of substance abuse (6.5) didn't appear to have any significance.

Table-VI

Individual factor and mental state

\begin{tabular}{lccc}
\hline $\begin{array}{l}\text { Individual factor } \\
\text { and mental state }\end{array}$ & Case & Control & OR $(95 \%$ CI $)$ \\
\hline Sleeping disturbance & $20(17.7)$ & $10(8.5)$ & $2.3(1.03,5.16)$ \\
H/o recent child birth & $1(1.4)$ & $3(3.3)$ & $1.7(0.63,7.23)$ \\
$\begin{array}{l}\text { History of substance } \\
\text { abuse }\end{array}$ & $6(5.3)$ & $1(0.9)$ & $6.5(0.77,54.9)$ \\
$\begin{array}{l}\text { Uncertainty about } \\
\text { future }\end{array}$ & $18(15.9)$ & $3(2.6)$ & $7.2(2.05,25.17)$ \\
$\begin{array}{l}\text { Impulsivity } \\
\begin{array}{l}\text { History of criminal } \\
\text { behavior }\end{array}\end{array}$ & $12(10.6)$ & $1(0.9)$ & $13.8(1.7,107.9)$ \\
\hline
\end{tabular}

Figure 1 Showing comparison among cases and controls where all five factors appeared to be significantly $(p=.001)$ different

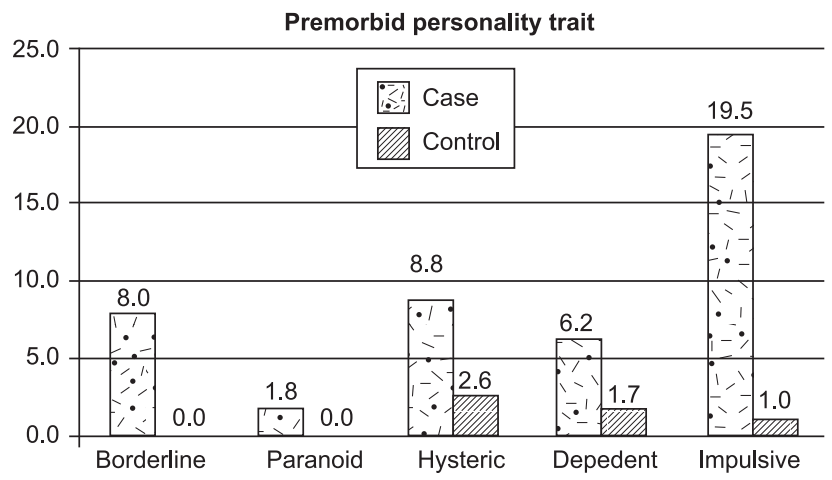

Fig.-1: Pre-morbid personality trait
Figure 2 Represent highly significant $(p=.0001)$ differences among cases and controls associated with adjustment disorder (case 29.2\%, control 0.9\%), mood disorder (case $12.4 \%$, control $0.0 \%$ ) and mood episode (case 8.0, control 0.9)

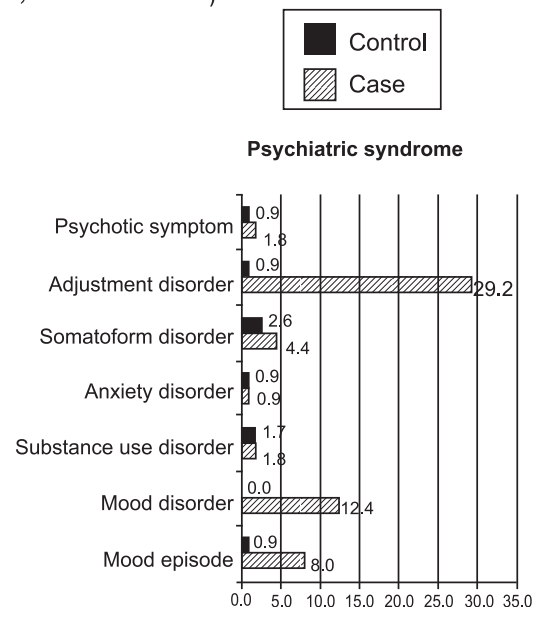

Fig.-2: Psychiatric syndrome

\section{Discussion}

In this research it was found that the married female from unitary family are more vulnerable to commit suicide or para suicide. The female to male ratio was almost 3:2.This findings were reverse of the figures in majority countries of the world where males were observed to commit suicide more than females 3. Ratio of suicide in male to female is about $3: 2,3: 1$ and 4:1 in India, Srilanka and UK respectively 9,10 . However this female predominance specially in young age group was also observed in another study of ICDDRB in Bangladesh ${ }^{5}$.

Here the age group 20-39 years were more vulnerable to commit suicide $(65.5 \%)$.It was similar to the previous findings of SEARC member countries where the most productive age group (15-29) are more vulnerable for suicide ${ }^{3}$.Another previous study from Bangladesh Revealed that the mean age of male victims was $25.6 \pm 11.1$ years and female was $23.6 \pm$ 9.0 years ${ }^{11}$.

Regarding the emotional factors the personal problem (23.9\%, OR 11.9) and economical hardship (18.6\%, OR 2.4) were more common risk factors for suicide, found in present study. These findings are similar with previous study, where the matrimonial conflict, family conflict and poverty were found the major reason for suicide 11 .

In present study researcher found that history of suicidal attempt by any relative (OR 4.2) and previous attempt to suicide (OR 7.4) appeared as highly significant factor for suicide. This findings are 
supported by another previous study in Bangladesh, where the family history of suicide or suicidal attempts were found among the $76.87 \%$ of cases.${ }^{11}$

. Further studies of the relationship of a family history of suicide to personality are needed in other populations and incorporating biologic measures.

Not being reared by biological parents (OR 3.2), marital disharmony (OR 4.0), and conflict within the family (OR 6.9) all of three factors appeared to be strongly associated with suicidal attempts among the present study. A study on Cameron Highlands in Malaysia revealed the similar findings about this issue. ${ }^{13}$ Cameron Highlands has one of the highest suicide rates in the world, especially among Indians. Forty Indian families (19 suicides; 21 controls) were studied to compare family characteristics such as income, overcrowding, birth order of index cases of suicide, family history of suicidal behavior or mental illness, marital disharmony, presence of alcohol abuse, availability of, and knowledge about, weedicides / insecticides, talk/threat of suicide among family members and experience of significant losses in the past year. Controls were matched for age, sex and educational level with the index cases of suicide. A significant difference was only found for one of the above factors, namely increased experience of significant losses in the past year in the family of index cases of suicide. More than $75 \%$ in both groups had alcohol related problems. About equal proportions in each group had a family history of suicidal behavior and mental illness. There was more marital disharmony in families of suicides but this failed to reach significance. ${ }^{14}$

In an Arab study on suicide significant associations were found between suicidal thoughts and behavior, and the presence of family history of suicide, all forms of psychopathology and suicidal behaviors. In addition, impulsivity and hostility were also significantly associated with suicidality. ${ }^{15}$

Among the individual factor and mental state sleeping disturbance and history of criminal behavior were highly significant. An Indian study is similar with the present findings. ${ }^{16}$ That study done in Bangalore, India has shown that several factors in the areas of family, marriage, education, occupation, general health, mental health and absence of protective factors contribute significantly for suicides. The cumulative and repetitive interaction of several factors in a complex manner results in suicides. The significant factors were presence of previous suicidal attempt in self (odds ratio $(O R)=42.62$ ), interpersonal conflicts and marital disharmony with spouse $(\mathrm{OR}=$ $27.98)$, alcoholism in self $(O R=23.38)$, presence of a mental illness $(\mathrm{OR}=11.07)$, sudden economic bankruptcy $(\mathrm{OR}=7.1)$, domestic violence $(\mathrm{OR}=6.82)$ and unemployment $(\mathrm{OR}=6.15)$. Individuals completing suicides did not have a positive outlook towards life, problem-solving approaches and coping skills. ${ }^{17}$

Premorbid personality trait acted as risk factor for suicide. Impulsive, hysteric and borderline traits are more vulnerable among the cases. The severity of anger and borderline personality features predicted history of suicidal attempts in the logistic regression model in a study done by Everen et al. ${ }^{17}$

Another study found consistent with the present study findings, that showed personality disorders had positive correlations with suicidal ideation and mixed relationships with aspects of reasons for living. Personality traits had negative correlations with suicidal ideation, with the exception of neuroticism, which had a positive relationship, and were mostly unrelated to reasons for living. In regression analyses, borderline and histrionic were the only personality disorders features that contributed significant variance in suicidal ideation, whereas neuroticism was the only personality trait that contributed significant variance in suicidal ideation. ${ }^{18}$

Here the researchers found highly significant $(p=.0001)$ differences among cases and controls associated with adjustment disorder (case 29.2\%, control $0.9 \%$ ), mood disorder (case $12.4 \%$, control $0.0 \%$ ) and mood episode (case 8.0, control 0.9) . WHO/ ISBRA study revealed the similar scenario, of the 1863 persons included in the WHO/ISBRA study, 292 had both a history of depressive symptoms and alcohol dependence or abuse and were included in the subgroup analysis. In the logistic regression analysis, drinking status, depressive symptoms, adverse drinking experiences during alcohol consumption, bad experiences from drug abuse and antidepressant therapy were found to be independent risk factors for suicidal attempt. Positive family history of alcoholism was a model-improving co-factor. This predictive model explains approximately $60 \%$ of the variance .19

Conclusion: This case control study on the risk factors of suicide in rural area of South-West Bangladesh revealed that the married female especially the younger from unitary family of low income group are more vulnerable to commit suicide or parasuicide. Several emotional factors like problem of love affair, personal problem and feeling of economic hardship appeared to have significant association with suicidal attempts. Presence of chronic diseases, suicidal 
attempts by any relative, not reared by biological parents, marital disharmony, conflict within the family, sleeping disturbance, uncertainty about future, impulsivity, history of criminal behavior, premorbid personality adjustment disorder, mood disorder and mood episode appeared to have significant association with suicidal attempts.

\section{References :}

1. World Health Organization: Background of SUPREPrevention of Suicide Behaviors-a task for all. http:// www.who.int/mental_health/prevention/suicide/ backgroun/en/

2. Bertolote JM \& Fleishmann A. A global perspective in the epidemiology of suicide. Suicidology Arg. 7, nr. 2, 2002 .

3. Gururaj G, Ahsan MN, Issac MK, Latif MA, Abeyasinghe $\mathrm{R} \&$ Tantipiwatanaskul P(eds). Suicide Prevention: Emerging From Darkness. World Health Organization, Regional Office for South East Asia, 2001.

4. Rahman HM. Socio-economic and Psycological Causes of Suicide in Jheneidah District. Department of Social Work, Rajshahi University, Bangladesh, 1986.

5. Mortality due to suicide in rural Bangladesh. ICDDR,B Health and science bulletin Vol. 1 No. 5 December 2003.

6. Vencova A. In: Issac MK\& Gururaj G. Epidemiology of suicide in Bangalore. NIMHANS, Bangalore, India, Publication No: 43, 2001.

7. Feroz A.H.M, Islam N SM, Reza S, Rahman M, Sen J, Mowla $\mathrm{M}$ et al. A community survey on the prevalence of Suicidal Attempts and Deaths in a selected rural area of Bangladesh. J Medicine 2012; 13(i):3-9.

8. Michael B.First,MD; Robert L.Spitzer,MD; Mirian Gibbon, M.S.W and Jannet B.W. Williams, D.S.W. The Structured Clinical Interview for DSM-IV Axis I Disorders (SCID-I) 1997. American Psychiatric Publishing.

9. Ahsan MN, Ahmed S, Alam FM \& Begum M. Attempted Suicide: An Overview. J Bang Coll Phy Sur, 1999; 17:108-119.
10. IssacMK \& Gururaj G. Epidemiology of Suicide in Bangalore. National Institute of Mental Health and Neuroscience, Bangalore, Publication No: 43, 2001.

11. Latif CMI, Nahar JS, Haque M, Jewel MSK, Suicidal Trends in Bangladesh: Existence of Regional Variation. Ban J of Psy, 2007, 21 (1): 28-39.

12. Nierenberg AA, Alpert JE, Gaynes BN, Warden D, Wisniewski SR, Biggs MM, Trivedi MH, Barkin JL, Rush AJ. Family history of completed suicide and characteristics of major depressive disorder: a STAR*D (sequenced treatment alternatives to relieve depression) study. J Affect Disord. 2008 May;108(12):129-34.

13. Roy A.Family history of suicide and neuroticism: a preliminary study. Psychiatry Res. 2002 May 15;110(1):87-90.

14. Maniam T. Family characteristics of suicides in Cameron Highlands: a controlled study. Med J Malaysia. 1994 Sep;49(3):247-51.

15. Hamdan S, Melhem N, Orbach I, Farbstein I, El-Haib M, Apter A, Brent D. Risk factors for suicide attempt in an Arab kindred. J Affect Disord. 2011 Jul;132(1-2):247-53.

16. Gururaj G, Isaac MK, Subbakrishna DK, Ranjani R. Risk factors for completed suicides: a case-control study from Bangalore, India. Inj Control Saf Promot. 2004 Sep;11(3):183-91.

17. Evren C, Cinar O, Evren B, Celik S.History of suicide attempt in male substance-dependent inpatients and relationship to borderline personality features, anger, hostility and aggression. Psychiatry Res. 2011 Nov 30;190(1):126-31.

18. Segal DL, Marty MA, Meyer WJ, Coolidge FLPersonality, Suicidal Ideation, and Reasons for Living among Older Adults. J Gerontol B Psychol Sci Soc Sci. 2011 Jul 16.

19. Yaldizli O, Kuhl HC, Graf M, Wiesbeck GA, Wurst FM, Risk factors for suicide attempts in patients with alcohol dependence or abuse and a history of depressive symptoms: a subgroup analysis from the WHO/ISBRA study. Drug Alcohol Rev. 2010 Jan;29(1):64-74 